\title{
A Comparison of Methods for Classifying Rhizosphere Bacteria
}

\author{
By P. G. BRISBANE AND A. D. ROVIRA \\ Division of Soils, Commonrealth Scientific and Industrial \\ Research Organization, Adelaide, Australia
}

(Received 20 February 1961)

\begin{abstract}
SUMMARY
A comparison was made between the following three methods of classifying bacteria: (1) division on associated characters, (2) identification by the use of Skerman's key, (3) classification by means of Affinity Index. Division on associated characters was of no value in this particular case. Skerman's key was adequate for the identification of the isolates, while the Affinity Index (a slight modification of the Similarity Index of Sneath) gave a comprehensive view of the relationships between isolates. It was considered that a random sample of 43 isolates selected from a collection of $\mathbf{3 1 8}$ rhizosphere bacteria formed a spectrum, rather than a series of groups.
\end{abstract}

\section{INTRODUCTION}

The reviews on rhizosphere bacteria (Clark, 1949; Katznelson, Lochhead \& Timonin, 1948; Starkey, 1958) indicate that the successful identification of all the rhizosphere isolates has not yet been achieved. Many workers have devised their own systems of classification, e.g. the nutritional classification (Lochhead \& Chase, 1943), morphology and gelatin digestion (Conn, 1948) and morphology, staining and dye tolerance (Clark, 1940). Sperber \& Rovira (1959) used Skerman's key (1959) of identification in Bergey's Manual (1957) to identify over $80 \%$ of their isolates to generic level. The isolates classified as Arthrobacter spp. by these authors were divided into 'arthrobacters' and 'arthrobacter-like-nocardias'. In a preliminary comparison between these isolates and type Arthrobacter spp. it became evident that there were certain generalized differences between Arthrobacter and the rhizosphere isolates. The main difference was in the coccal form; $\boldsymbol{A}$. globiformis breaks up completely into perfect spheres while the rhizosphere isolates formed coccobacilli, with some rods in most older cultures. A. globiformis had certain of its stages Grampositive, whereas the rhizosphere isolates did not show this Gram-variable characteristic; also, there were differences in the metabolic patterns. As a consequence of these observations it was decided to re-examine the complete data collected by Sperber \& Rovira on their 318 isolates.

The principle of division on associated characters suggested by Sneath (1957a) was attempted with the 318 isolates. It was not possible to use the Similarity Index system of Sneath, as no electronic computer was available. In addition to this reexamination of existing results, 43 cultures were selected at random from the Sperber-Rovira collection, and together with 21 known cultures were subjected to a 
further series of tests. The results from these tests were used to group and identify the cultures by three methods, the details of which appear in this paper together with the re-examination of the original results.

\section{METHODS}

Organisms. The original collection of rhizosphere isolates of Sperber \& Rovira (1959) was maintained at $4^{\circ}$ and subcultured on yeast extract-peptone-soil extract (YPS) agar (Bunt \& Rovira, 1955) at intervals of 6 months. The named cultures from various laboratories listed below were:

Achromobacter A1, Achromobacter A2 (University of Melbourne); Agrobacterium radiobacter NCIB 8149 (Department of Scientific and Industrial Research, England); Arthrobacter aurescens, A. citreus, A. globiformis, A. simplex, A. ureafaciens (Department of Agricultural Science Service Laboratories, Ottawa, Canada); Bacillus subtilis NCTC 6342, Flavobacterium sp. (University of Melbourne); Micromonospora sp. (University of Sydney); Nocardia asteroides NCTC 6761, N. rubra (University of Sydney); Pseudomonas fluorescens (University of Adelaide); P. medicaginis, P. syringae (University of Melbourne); Rhizobium trifolii (from D. Norris, C.B. 721 from Trifolium polymorphum), R. meliloti (Q.A. 867 from Rothamsted), Rhizobium sp. (from G. D. Bowen Q.A. 549 from Centrosema pubescens); Streptomyces venezualae (University of Sydney); Xanthomonas campestris (University of Melbourne).

Basal medium. The yeast-extract peptone nitrate broth of Sperber \& Rovira (1959), with $15 \mathrm{~g}$. agar/l. for solid medium, was used.

Gelatin agar. Gelatin $(0 \cdot 4 \%, \mathrm{w} / \mathrm{v})$ in basal agar. Hydrolysis was observed by flooding the plates with saturated ammonium sulphate following incubation at $26^{\circ}$ for 7 days.

Starch agar. Starch $(\mathbf{0 . 2} \%, \mathrm{w} / \mathrm{v})$ in basal agar. Hydrolysis was observed by flooding the plates with iodine solution after 7 days at $26^{\circ}$.

Casein agar. Ten ml. of sterile $9 \%(\mathrm{w} / \mathrm{v})$ solution of powdered milk were added to every $100 \mathrm{ml}$. basal agar immediately before pouring plates. Hydrolysis was observed as a clearing round the colony.

High $\mathrm{pH}$ medium. Difco veal infusion (23 g.) and $15 \mathrm{~g}$. agar/l. water; finally adjusted to $\mathrm{pH} \mathbf{8} \cdot \mathbf{5}$.

Nutrient agar. Oxoid nutrient agar.

Apatite agar. As used by Sperber (1958).

Peptone yeast extract (PY) broth. Peptone (10 g.), Difco yeast extract (5 g.), sodium chloride $\left(5 \mathrm{~g}\right.$.)/l. water. $\mathrm{H}_{2} \mathrm{~S}$ production was determined with lead acetate filter paper strip in the mouth of the tube.

Methylene blue agar. Basal agar $+1 \%(\mathrm{w} / \mathrm{v})$ glucose and $1 \mathrm{ml} . / \mathrm{l}$. of $0.5 \%(\mathrm{w} / \mathrm{v})$ methylene blue was tubed in $10 \mathrm{ml}$. lots and inoculated before setting. Those isolates which reduced more than half the depth of the agar were considered positive.

Sucrose mannitol sauerkraut (SMS) broth. Sucrose (5 g.), mannitol (5 g.), sauerkraut juice $(20 \mathrm{ml}$.$) , sodium citrate (1 \mathrm{~g}$.), magnesium glycerophosphate (1 g.), Casamino acids (1 g.), ammonium nitrate (0.1 g.), distilled water $1000 \mathrm{ml}$. (Harris, J. R., personal communication). This medium was used to demonstrate fluorescence when the selected cultures were retested.

Ulrich's milk. The reaction was recorded after 15 days at $26^{\circ}$ (Ulrich, 1944). 
Glucose broth. Ten g. glucose, $1 \mathrm{~g}$. Difco yeast extract, $0 \cdot 4 \mathrm{~g} \cdot \mathrm{K}_{2} \mathrm{HPO}_{4}, 0 \cdot 5 \mathrm{~g}$. $\mathrm{KNO}_{3}, 0.05 \mathrm{~g} . \mathrm{MgSO}_{4} \cdot 7 \mathrm{H}_{2} \mathrm{O}, 0 \cdot 1 \mathrm{~g} . \mathrm{NaCl}, 0 \cdot 17 \mathrm{ml} .6 \%(\mathrm{w} / \mathrm{v})$ solution of ferric citrate, $4 \mathrm{ml}$. indicator (equal parts of saturated aqueous bromcresol purple and cresol red) in 1 l. water.

Sucrose broth. As for glucose broth but with $10 \mathrm{~g}$. sucrose. One series of sugar broths was incubated aerobically, the other anaerobically by the steel wool technique of Parker (1955).

Sensitivity to antibiotics. This was tested by surface seeding basal agar plates with cultures and then placing one Oxoid 'Multodisk'(11-14D)/plate. Each disk contains eight peripheral disks-one for each of the following: chloramphenicol (50 $\mu \mathrm{g}$.$) ,$ erythromycin (50 $\mu \mathrm{g}$.), sulphafurazole (500 $\mu \mathrm{g}$.), novobiocin (30 $\mu \mathrm{g}$.), oleandomycin (10 $\mu \mathrm{g}$.), penicillin (5 units), streptomycin (25 $\mu \mathrm{g}$.), tetracycline (50 $\mu \mathrm{g}$.). The zones of inhibition were recorded after incubation for 7 days at $26^{\circ}$.

\section{Examination of original data}

The data previously collected by Sperber \& Rovira (1959) from a series of 19 tests on 318 rhizosphere isolates were used. The two tests, namely, colour and fluorescence which were performed on two media were recorded as follows : colour 1 was presence of pigment in colonies on apatite agar; colour 2 was presence of pigment on nutrient agar; fluorescence 1 was obtained on yeast extract mannitol agar; fluorescence 2 on nutrient agar.

The results were transferred to edge-punched cards, one card for each isolate. Holes were punched for positive values and left blank for negative values. The total number of isolates positive for each test was counted, and those tests which did not have some positive and some negative isolates were discarded. Three tests were discarded for this reason, namely, the breakdown of cellulose (all negative), the nodulation of subterranean clover (all negative) and growth in peptone water (all positive).

A $2 \times 2$ table was set up for each combination of the remaining 16 tests and $\chi^{2}$ values calculated for each of the 120 tables. When the association was significant at the $1 \%$ level, the degree of association was measured by using Yule's coefficient of association (the $\mathbf{Q}$ value). Moroney (195\%) set out the methods used in these calculations. Sneath $(1957 a)$ has pointed out that the associations revealed by these calculations may be due to two expressions of the one character, and when discovered such associations should be removed. For this reason the closely associated characters 'dissolving of apatite' $\times$ 'acid production' (Sperber, 1958) and 'colour 1' $\times$ ' colour 2 ' were removed from the calculations.

\section{RESULTS}

\section{Examination of original data}

The data obtained by Sperber \& Rovira (1959) from 16 tests on 318 rhizosphere isolates were examined by the methods set out above. Table 1 shows the $Q$ values for these isolates and the algebraic sum of the $\mathbf{Q}$ values for each test. The highest $\mathbf{Q}$ value in Table $\mathbf{1}, \mathbf{- 0 . 8 6}$, was for Gram reaction against growth on high $\mathrm{pH}$ medium. Of the 249 isolates which grew on the high $\mathrm{pH}$ medium only 19 were Gram-positive. All the other $Q$ values were low, the lowest being only -0.29. The total $Q$ values 
(disregarding sign) for ammonia production and colour 1 were similar. Colour 1 was significantly associated with eight other characters (disregarding colour 2), whereas ammonia production was associated with seven other characters. Colour 2 had a much lower total $Q$ value than colour 1 . The selection of a character for division was difficult; those characters strongly associated with some characters, namely, Gramreaction and colour 2, were not associated with enough characters to give them a high total $Q$ value. The characters which were associated with a large number of other characters had high total $\mathbf{Q}$ values, even though they had only moderate or low degrees of association.

\title{
Table 1. Q values significant at the $1 \%$ level for 318 rhizosphere isolates
}

\begin{abstract}
Only half the table of $Q$ values is shown, the blank part being the mirror image of the part below. The total number of isolates positive for each test and the algebraic sum of the $Q$ values are also shown. $\mathbf{C 1}=$ colour $1, A p=$ solution of apatite, $A c=$ acid production from glucose, $\mathrm{Gr}=\mathrm{Gram}$ reaction, $\mathrm{H}_{2} \mathrm{~S}=\mathrm{H}_{2} \mathrm{~S}$ production from peptone, $\mathrm{NH}_{3}=\mathrm{NH}_{3}$ production from peptone, $\mathrm{NO}_{2}^{-}=\mathrm{NO}_{2}^{-}$production from nitrate, $\mathrm{Mo}=$ motility, $\mathrm{Ca}=$ catalase, $\mathrm{Ge}=$ gelatine hydrolysis, $\mathbf{F 1}=$ fluorescence $1, \mathrm{pH}=$ growth on high $\mathrm{pH}$ medium, $\mathbf{C 2}=$ colour 2, F2 = fluorescence $2, \mathrm{Y}=$ presence of $\mathrm{Y}$ forms. $\mathrm{Pl}=$ presence of pleomorphic forms.
\end{abstract}

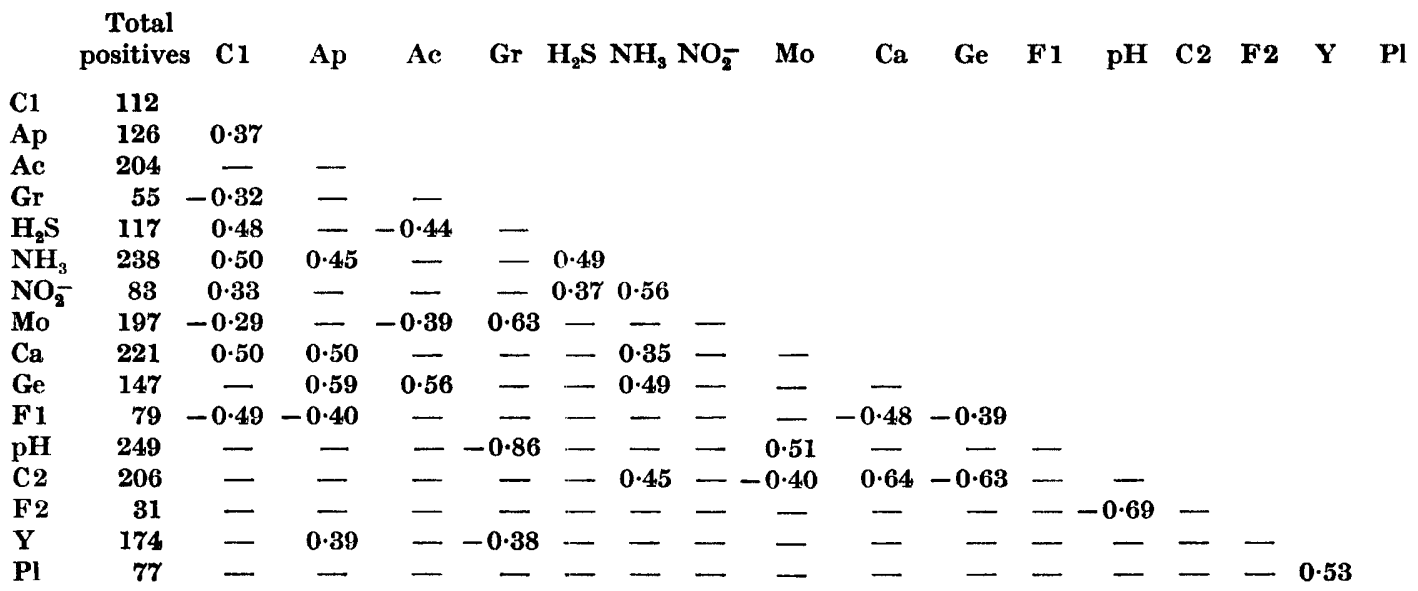

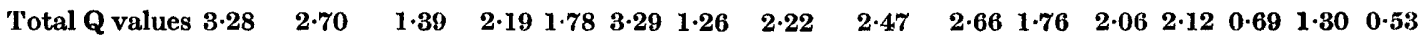

The most important character should have a large number of other characters strongly associated with it, therefore the character which had the highest algebraic sum of its $Q$ values was considered the most important for division. Table 1 shows that ammonia production had the highest total $Q$ value (3.29), so the isolates were divided on ammonia production (see Fig. 1). The two resulting groups, the ammoniaproducing group and the non-ammonia-producing group, were treated in exactly the same manner as the original isolates, i.e. all possible associations were tested for significance, and those found significant at the $1 \%$ level measured by the $Q$ test. The resultant $Q$ values were then algebraically summed and the character with the highest algebraic sum of $\mathbf{Q}$ values used for the next division. This character was gelatin hydrolysis for the ammonia-producing group, and growth on high $\mathrm{pH}$ media for the non-ammonia-producing group. Division was continued in this way until there was no character that was significantly correlated with any other two characters. 


\begin{tabular}{|c|c|c|c|c|c|c|c|c|c|c|c|c|c|c|c|}
\hline & & pH & Ge & $\mathrm{Ca}$ & St & Ap & $\mathrm{Me}$ & Po & UA & UB & $\mathbf{N H}_{3}$ & $\mathrm{NO}_{2}^{-}$ & $\mathrm{H}_{2} \mathrm{~S}$ & $\mathrm{Ga}$ & \\
\hline $\mathrm{pH}$ & 54 & & & & & & & & & & & & & & \\
\hline Se & 33 & - & & & & & & & & & & & & & \\
\hline $\mathrm{Ca}$ & 19 & - & 0.95 & & & & & & & & & & & & \\
\hline $\mathbf{S}$ & 23 & - & - & 0.77 & & & & & & & & & & & \\
\hline Ap & 21 & - & - & - & - & & & & & & & & & & \\
\hline ic & 2 & - & - & 0.58 & - & - & 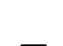 & & & & & & & & \\
\hline Po & 31 & - & - & 0.53 & 0.49 & - & - & & & & & & & & \\
\hline$\Lambda$ & 13 & - & 0.61 & - & - & - & - & - & & & & & & & \\
\hline UB & 30 & - & -0.52 & -0.46 & - & -- & - & - & - & & & & & & \\
\hline $\mathrm{NH}_{3}$ & 5 & $0.84 *$ & - & - & - & - & - & - & - & - & & & & & \\
\hline $\mathrm{NO}_{2}^{-}$ & 2 & - & -0.62 & - & - & - & - & - & - & - & - & & & & \\
\hline${ }_{2} \mathrm{~s}$ & 2 & - & - & - & - & $\ldots$ & - & - & - & 0.56 & & -- & & & \\
\hline & 28 & - & - & 0.51 & - & - & - & - & $0.93 *$ & $-0.74^{*}$ & $\cdots$ & - & - & & \\
\hline Gn & 8 & - & - & - & - & - & - & - & - & - & $\cdots$ & -- & - & 0.99 * & \\
\hline & 23 & - & - & - & $\ldots$ & - & - & - & $0.81^{*}$ & $-0.62^{*}$ & - & $\ldots$ & - & $0 \cdot 87^{*}$ & \\
\hline Sn & 9 & - & - & - & - & - & - & - & - & -0.82 & - & - & - & - & \\
\hline & 14 & - & - & - & - & - & - & - & - & - & - & - & - & - & - \\
\hline$C_{1}$ & 40 & - & - & 0.58 & - & - & - & - & - & - & - & $\cdots$ & - & - & \\
\hline & 20 & - & - & - & - & - & - & - & - & -0.50 & - & - & - & - & \\
\hline h & 54 & - & -- & -- & - & $-0.85^{*}$ & - & - & - & - & $\ldots$ & - & - & - & \\
\hline Er & 41 & $\ldots$ & - & - & $0 \cdot 61$ & - & - & - & - & - & - & - & - & 0.53 & \\
\hline & 41 & - & - & - & $0.73 *$ & - & - & - & - & - & - & - & - & -- & \\
\hline 0 & 4 & - & -- & - & - & -0.75 & - & $\ldots$ & .- & - & - & - & - & - & \\
\hline 0 & 1. & - & - & - & $0 \cdot 65$ & - & -. & - & - & - & $\ldots$ & - & $\ldots$ & - & \\
\hline & 14 & - & - & -- & .. & - & - & - & - & - & -. & & - & - & \\
\hline & 56 & - & -- & ... & - & - & -- & - & - & - & ..- & -. & $\ldots$ & - & \\
\hline & il & - & $\ldots$ & - & - & - & - & $\cdots$ & & - & -. & - & - & - & \\
\hline & 18 & .- & - & 0.52 & 0.58 & - & - & 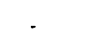 & & - & - & - & - & - & \\
\hline & 17 & - & - & - & - & - & $\ldots$ & - & - & - & - & - & -- & - & \\
\hline & i1 & - & - & $\ldots$ & & - & - & $-0 \cdot 69$ & $\ldots$ & - & $-0.91 *$ & - & - & - & \\
\hline & 21 & - & - & - & - & $\ldots$ & -. & - & - & - & - & $\ldots$ & $\ldots$ & - & \\
\hline
\end{tabular}

$\begin{array}{lllllllllllllll}\text { Total Q values } & 0.84 & 2.70 & 4.90 & 3.83 & 1.60 & 0.58 & 1.71 & 2.35 & 4.22 & 1.75 & 0.62 & 0.56 & 4.57 & 2.78\end{array}$

Those $\mathbf{Q}$ values marked * were significant at $1 \%$. Only half the table is shown, the part left blank being the mirror image of the part below. The total number of bacteria positive for each test and the algebraic sum of the values are shown.

$\mathrm{pH}=$ growth in high $\mathrm{pH}$ medium, $\mathrm{Ge}=$ gelatin liquefaction, $\mathrm{Ca}=$ casein digestion, $\mathrm{St}=$ starch hydrolysis,

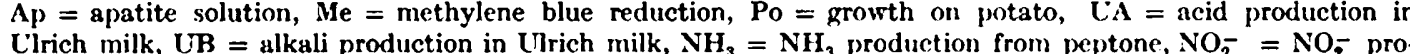

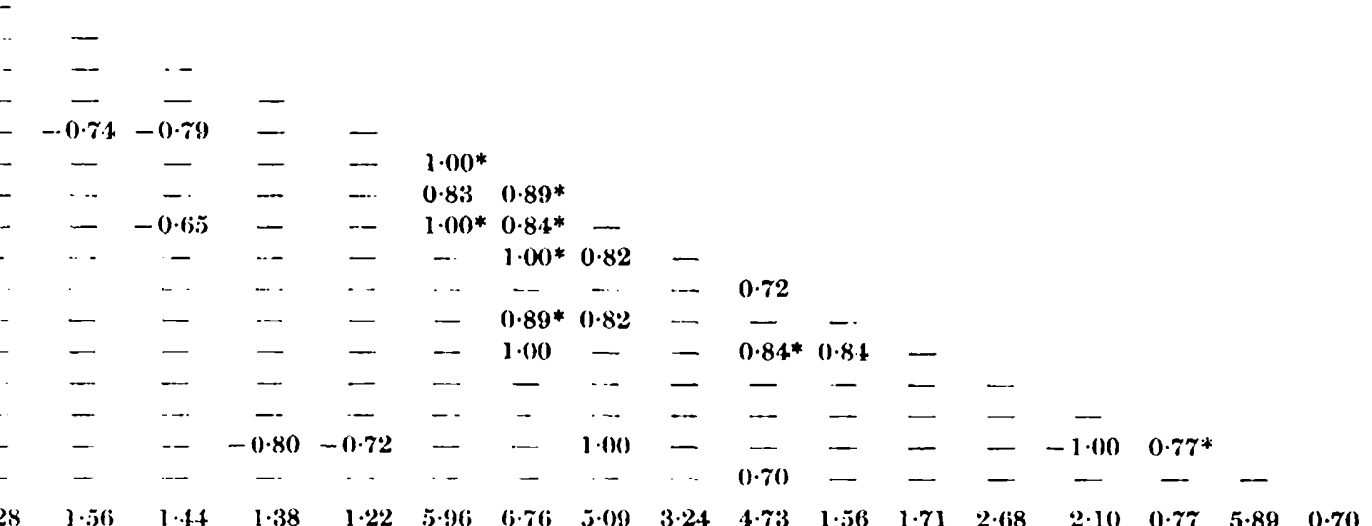

duction from $\mathrm{NO}_{-}, \mathrm{H}_{\mathrm{S}} \mathrm{S}=\mathrm{H}_{2} \mathrm{~S}$ from peptone, $\mathrm{Ga}=$ acrobic; acid from glucose, $\mathrm{Gn}=$ anaerobic, acid from glucose, $\mathrm{Sa}_{\mathrm{a}}=$ acrobic; acid from sucrose, $\mathrm{Sn}=$ anacrobic; acid from sucrose, $\mathrm{F}$ = fluorescence (SNS), $\mathrm{Cl}=$ colvur 1. $\mathrm{C} 2=$ colour $2, \mathrm{Ch}=$ chloramphenicol sensitivity, $\mathrm{Er}=$ erythromycin sensitivity, $\mathrm{Su}=$ sulphafurazole sensitivity, $\mathrm{No}_{\mathrm{O}}=$ novobiocin sensitivity, $\mathrm{Ol}=$ oleandomycin sensitivity, $\mathrm{P}_{\mathrm{e}}=$ penicillin sensitivity, $\mathrm{St}=$ streptoinycin sensitivity, $\mathrm{Gr}=\mathrm{Gram}$ reaction, $\mathrm{Fi}=$ filamentous forms present, $\mathrm{Y}=\mathrm{Y}$ forms present, $\mathrm{Pl}=$ pleomorphic forms present, $\mathrm{Co}=$ coccal forms present. 
The $\mathbf{Q}$ value table for the first division (Table 1 ) is the only one presented here in order to conserve space. The six groups which resulted from this division on associated characters are given in Fig. 1, but a comparison with the identification by Sperber \& Rovira (1959) showed that each group contained several genera. In view of the heterogeneity of the groups, the second part of this investigation was undertaken using typed cultures as well as the selected rhizosphere isolates.

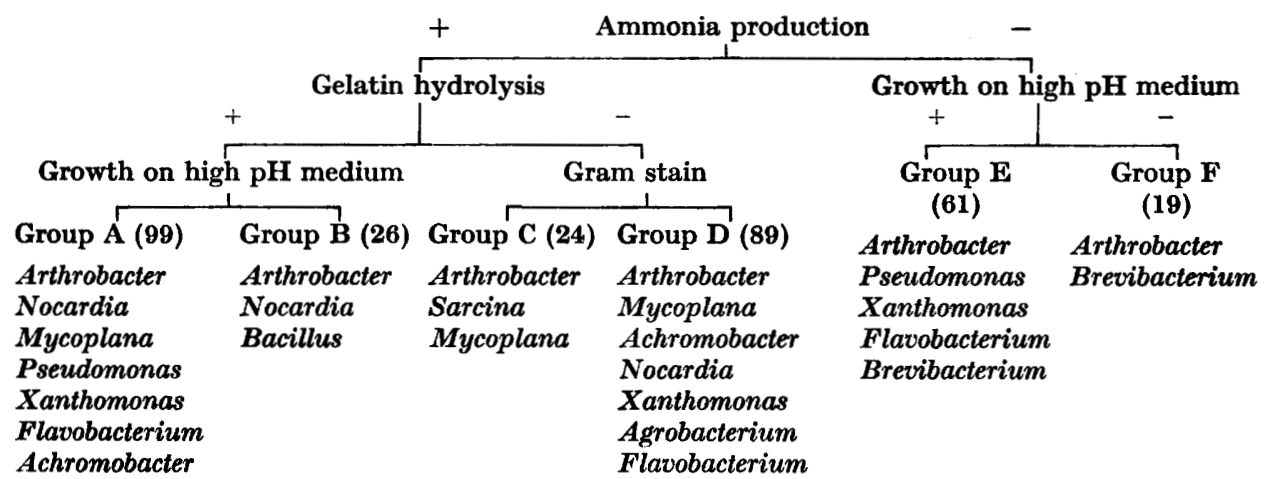

Fig. 1. Division of the 318 rhizosphere isolates using associated characters as shown. Positive reactions are on the left, negative reactions on the right. The number of isolates in each group is shown in brackets and the principal genera as identified by Sperber \& Rovira (1959) are listed for each group.

\section{Retesting of selected bacteria}

The morphological, cultural, biochemical and antibiotic sensitivity characteristics of 21 named cultures and 43 rhizosphere isolates were studied. Forty-one characters were recorded as positive or negative on edge-punched cards. Of these characters, thirty-one were used to determine the $Q$ values (Table 2). The most notable feature of Table 2 was the small number, 28 , of associations significant at the $1 \%$ level, as compared with 35 in Table 1, even though the number of tests had risen from 16 to 31 increasing the number of possible associations from 120 to 535 . The decrease in numbers of significant associations at the $1 \%$ level can be attributed to the lower number of organisms used in the second case, making it less likely to obtain significant results. For this reason the significance level was set at $5 \%$ and the $Q$ values of Table 2 have been worked out for associations significant at this level.

A decision had to be made as to which of the associations should be removed in accordance with the principles laid down by Sneath; to conform with Table 1 the associations of colour $1 \times$ colour 2 and dissolving of apatite $\times$ acid production were removed. The removal of other associations may be justified, but, as it was considered that inclusiveness was better than exclusiveness no further associations were removed. In comparing Table 1 with Table 2, the only common associations found were colour $1 \times$ colour 2 ; dissolving of apatite $\times$ acid production, and pleomorphism $\times \mathrm{Y}$ forms. The association of growth at high $\mathrm{pH}$ value $\times$ Gram reaction, which was the highest in Table 1, does not appear in Table 2, indicating that the association probably was spurious. When this association was disregarded the $Q$ values (ignoring sign) of Table 1 ranged from $0 \cdot 29$ to $0 \cdot 69$ and those in Table 2 from $0 \cdot 46$ to $1 \cdot 00$. 
If the levels of significance in both tables had been adjusted so that only $\mathbf{Q}$ values above a given figure (say $0 \cdot 8$ ) were recorded, then there would be more associations in Table 2. The greater range of bacteria and tests used for Table 2 accounted for the greater number of high associations in Table 2 than in Table 1, e.g. the association between Gram-positivity and erythromycin susceptibility could be demonstrated only when there was sufficient Gram-positive organisms and when the test for erythromycin susceptibility was performed.

A system of division was built up for the 64 bacteria by using the methods described for Fig. 1, the only difference being that a $5 \%$ level of significance was used. These results appear in Fig. 2. Erythromycin susceptibility had the highest total $Q$ value $(6 \cdot 76)$ in Table 2, and was used to make the first division in Fig. 2. This is a good character to divide on, as it has a large number of characters strongly associated with it. Pleomorphic forms also had a high total $Q$ value of 5.89. Five groups resulted from the system of division set out in Fig. 2. The fact that three out

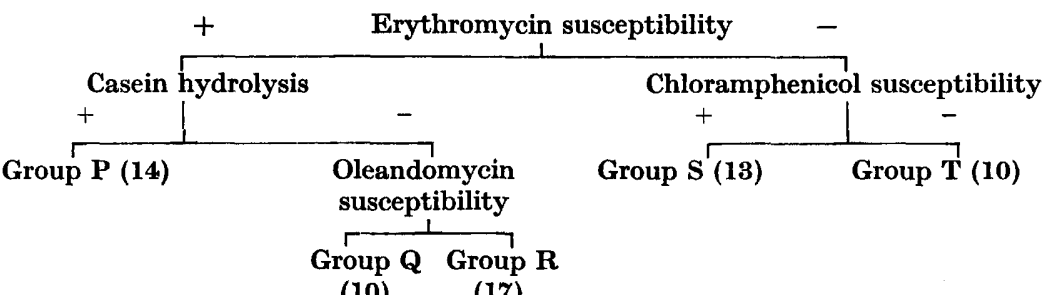

$\begin{array}{lc}\text { Group P } & \begin{array}{c}\text { Group Q } \\ \text { Arthrobacter }\end{array} \\ \text { aurescens } & \begin{array}{c}\text { globiformis } \\ \text { A. citreus }\end{array} \\ \text { Bacillus subtilis } & \\ \text { Micromonospora } & \text { A. simplex } \\ \text { sp. } & \\ \text { Streptomyces } & \\ \text { venezualae } & \\ \text { Xanthomonas } & \\ \text { campestris } & \end{array}$

Group $\mathbf{R}$
Nocardia rubra
Rhizobium trifolii
Flavobacterium sp.
Pseudomonas
syringae

\begin{tabular}{|c|c|}
\hline $\begin{array}{c}\text { Group S } \\
\text { Rhizobium } \\
\text { meliloti }\end{array}$ & $\begin{array}{c}\text { Group T } \\
\text { Achromobacter A } 1\end{array}$ \\
\hline $\begin{array}{l}\text { Nocardia } \\
\text { asteroides }\end{array}$ & Achromobacter A2 \\
\hline $\begin{array}{l}\text { Agrobacterium } \\
\text { radiobacter }\end{array}$ & $\begin{array}{l}\text { Arthrobacter } \\
\text { ureafaciens } \\
\text { Pseudomonas } \\
\text { fluorescens } \\
\text { P. medicaginis } \\
\text { Rhizobium sp. }\end{array}$ \\
\hline
\end{tabular}

Fig. 2. Division of 64 bacteria on the basis of associated characters. Positive reactions are on the left, negative reactions on the right. The number of bacteria in each group is shown in brackets. The named bacteria within each group are also shown.

of the four characters used for division were reactions to antibiotics was not entirely due to associations between the various antibiotics. In the group of 23 bacteria that formed the erythromycin-resistant group, chloramphenicol-sensitivity was negatively associated with: dissolving of apatite, acid production in Ulrich's milk, aerobic production of acid from glucose, anaerobic production of acid from sucrose, and fluorescence; and it was positively associated with novobiocin sensitivity. In the group of 27 bacteria sensitive to erythromycin and not attacking casein, oleandomycin sensitivity was positively associated with the breakdown of starch, the solution of apatite and the presence of cocci.

The groups formed in Fig. 2 have been labelled P, Q, R, S, T, to facilitate comparison with the groups obtained from the 318 isolates (Fig. 1). The named cultures have been listed under the groups to which they belonged. In general each group 
contained several genera except for group $\mathbf{Q}$, in which only three Arthrobacter spp. occurred.

A comparison of the groupings of the 43 rhizosphere isolates common to Fig. 1 and Fig. 2 is given in Table 3. This shows a poor coincidence of groups, e.g. group $\mathbf{Q}$ isolates identified as Arthrobacter spp. included members from groups A, D, E, and F. Therefore it was impossible to use Fig. 2 to identify any of the groups $\mathbf{A}$ to $\mathbf{F}$ from Fig. 1.

Owing to the failure of the system of division on associated characters to give satisfactory groupings of the named cultures, the 64 cultures were traced through

Table 3. A comparison of the groupings of the 43 isolates common to both Fig. 1 and Fig. 2

\begin{tabular}{lrrrrrrr}
$\begin{array}{c}\text { Groups } \\
\text { from }\end{array}$ & \multicolumn{7}{c}{ Groups from Fig. 1 } \\
Fig. 2 & A & B & C & D & E & F & Totals \\
P & 6 & 1 & - & 1 & 1 & - & 9 \\
Q & 1 & - & - & 3 & 1 & 2 & 7 \\
R & 3 & 2 & - & 4 & 4 & - & 13 \\
S & 1 & - & 1 & 5 & 3 & - & 10 \\
T & 2 & - & - & 2 & - & - & 4 \\
Totals & 13 & 3 & 1 & 15 & 9 & 2 & 43
\end{tabular}

Skerman's key of Bergey's Manual (1957); the results are given in Table 4. Of the seven rhizosphere isolates which were considered to be Arthrobacter spp. in Fig. 2, only one was identified as such by the key. It would appear that many of the named isolates were incorrectly identified. This was the fault of the testing procedures rather than of the key, e.g. Rhizobium spp. fell into the Pseudomonas-Alcaligenes group because there was no satisfactory way of identifying Rhizobium except on its ability to nodulate legumes, a test which is virtually impossible to perform against all legumes. The lack of a successful routine technique for determining flagellation was also a great handicap.

Although the use of Skerman's key resulted in the naming of organisms, quite different isolates often appeared to belong to the same genus because they were identical only in the characters listed in the key, while they varied in a great number of other characters. This arbitrary nature of the key exists because of the lack of comparative studies with a wide range of organisms. Sneath's method of calculating Similarity Index would seem the ideal way of making such comparative studies. It was therefore decided to modify the method slightly so that it could be used for these isolates without the use of an electronic computer. The modifications made were that negative similarities were considered as important as positive similarities, and all characters which were entirely positive or entirely negative were omitted. Of the forty-one characters recorded there were thirty-nine that could be used on this basis. To avoid confusion the modified index was called the 'Affinity Index' (AI) and it may be expressed as

$$
\text { Affinity Index }=\frac{\text { No. of characters in common }}{\text { Total No. of characters considered }} \times 100 \% \text {. }
$$

The punch cards which had been prepared for determination of associated characters in the 64, isolate groups were used to determine the Affinity Indices. The denominator 


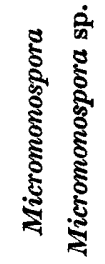

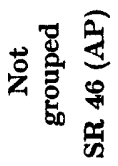
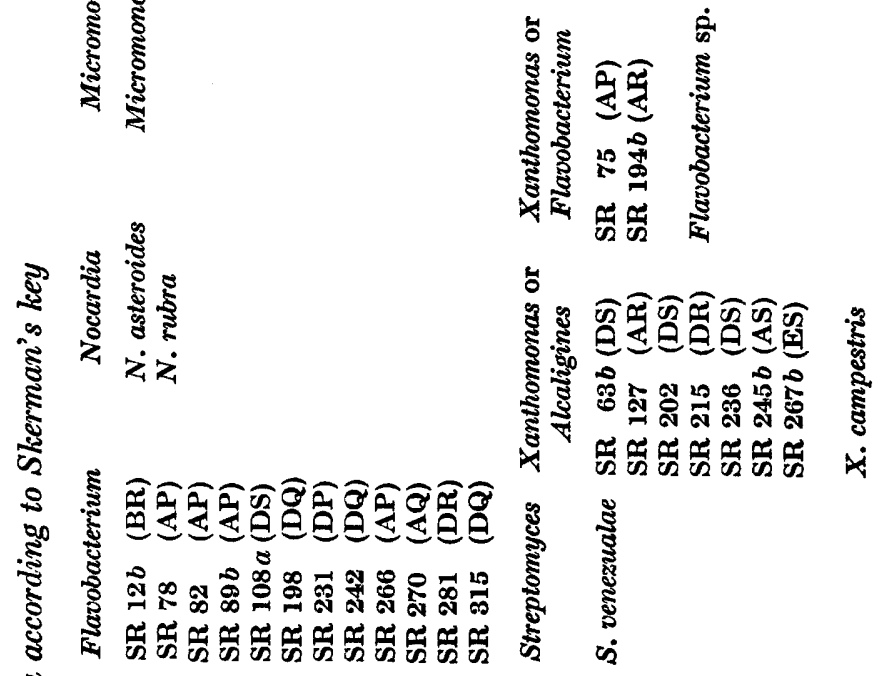

䑻

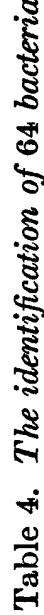

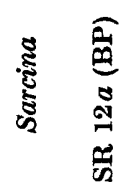

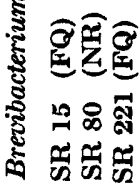

芯

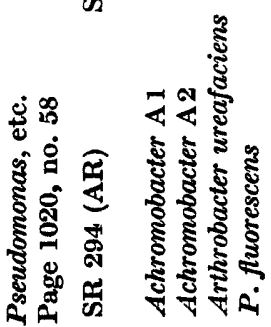

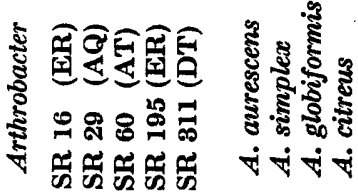
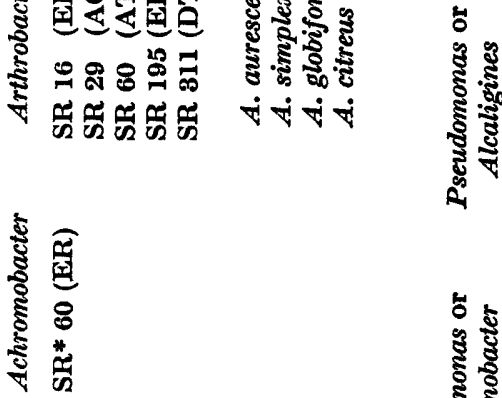

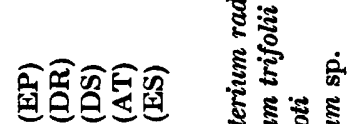

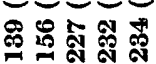

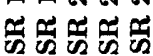

ชิ
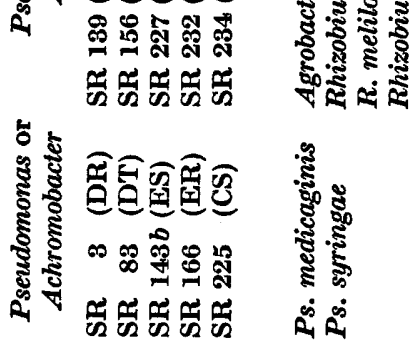
of the expression given above was constant at 39, i.e. the number of tests having some positive and some negative values, and the numerator was determined for each possible pair of isolates. The border of the first card was stained red and compared with the second and subsequent unstained cards. Comparison was made by placing the red card 1 on white card 2 when any test positive (punched) on 1 but negative (not punched) on 2 showed as a white space in a red gap and these spaces were counted. The two cards were then turned over so that white card 2 now lay on red card 1 and any test positive on 2 but negative on 1 showed as a red space filling a white gap. These spaces were counted. The sum of these two totals, which gave the number of tests different between 1 and 2 , was recorded. The number of tests in common was the total number (39) less the number of tests which differed. Having obtained the number of tests which differed between cards 1 and 2, card 1 was then compared with card 3 and so on until 1 had been compared with all the cards. Card 2 was then stained and compared with all the unstained cards. In this way over 2000 Affinity Indices were calculated, a difference of four or less characters corresponded to an Affinity Index of $90 \%$, a difference of five or six characters corresponded to an Affinity Index of $85 \%$ and a difference of seven or eight characters corresponded to an Affinity Index of $80 \%$. Having obtained Affinity Indices in this way, the results were sorted in the manner suggested by Sneath, the most closely related being put together first and the grouping extended as the relationship decreased. The relationships discovered are shown in a linear manner in Table 5 . The name or SR number of the isolate is given in the left-hand column, the code number used in this investigation is shown in the second column, then follows a list of the code numbers of all cultures with an Affinity Index of $80 \%$ or more. Thus Rhizobium sp. isolated from Centrosema pubescens Benth. was related with an $80 \%$ Affinity Index to SR 225 and to Rhizobium meliloti. The cultures at the extreme ends of Table 5 were unrelated to each other or to the cultures in the centre of the table and their order was of no taxonomic significance. The normal way of showing relationships of this type, as used in other papers (Sneath, 1957b; Sneath \& Cowan, 1958; Hill, 1959) is set out in Fig. 3, in which the squares show those cultures which differ by no more than eight characters and the triangles show those cultures which are dissimilar by twenty or more characters.

A sorting which resulted in a good arrangement was typified by having related isolates close together. When this occurred in Fig. 3 the dark squares representing high affinity lay close to the diagonal. Although this condition was reasonably fulfilled, there was no block of closely related organisms, which indicated that there were no well defined groups of isolates. There was a large group of isolates in the centre, composed mainly of rhizosphere isolates which formed a spectrum of related bacteria rather than a series of related groups. The known bacteria which had the highest affinity to this large spectrum were Agrobacterium radiobacter (no. 51), Xanthomonas campestris (no. 70), and two Rhizobium sp. (nos. 65 and 66). Above the large group was a small group consisting of Achromobacter A1 and A2 (nos. 49 and 50), Flavobacterium sp. (no. 58), Pseudomonas fluorescens (no. 62), Arthrobacter ureafaciens (no. 56) and SR 83 (no. 15). The culture which was labelled 'Arthrobacter ureafaciens' differed in morphology, colony colour, motility, hydrogen sulphide and acid production from the description for this organism given by Bergey's Manual (1957). With the exception of Flavobacterium sp. which was poorly chromogenic 
Table 5. The relationships between 64 cultures according to the Affinity Index

Column 1 shows the name or number of the culture and column 2 the code number. On the right of the table are shown the code numbers of all the bacteria having $80 \%$ or more affinity with each of the 64 cultures. Italic figures indicate $85 \%$ affinity, bold figures $90 \%$ affinity.

\section{Name or no.}

SR 60

Arthrobacter aurescens

Rhizobium sp.

SR 294

SR 311

Achromobacter A1

Achromobacter A2

Flavobacterium sp.

Pseudomonas fluorescens

Arthrobacter ureafaciens

SR 83

SR 245 B

Pseudomonas syringae

SR 225

Arthrobacter citreus

A. globiformis

A. simplex

Pseudomonas medicaginis

SR 69

SR 166

Rhizobium trifolii

R. meliloti

SR 80

Agrobacterium radiobacter

SR 156

SR 215

SR 227

SR 134, B

SR 301

SR 281

SR 270

SR 127

SR $12 B$

SR 195

SR 3

SR 16

SR 236

SR 267

SR 108A

SR 232

SR 139

Xanthomonas campestris

SR $89 B$

SR 82

SR 231

SR 234

SR 63B

SR 194B

SR 75

SR 78

SR 315

SR 242
Code

no.

8

52

68

45

47

49

50

58

62

56

15

40

64

32

53

54

55

63

10

23

65

66

13

51

22

30

33

20

46

44

43

19

3

26

1

5

37

42

17

35

21

70

16

14

34

36

9

25

11

12

48

39
32,66

23, 44

51

50

$49,56,62$

62,56

56, $15,58,50$

$62,15,50,58$

$56,62,63$

33

33

$3,20,66,68$

13

55

54, 23

10,15

$23,65,13,22,44,63$

$10,65,22,1,26,55,45,66$

$23,10,13,22,66,1,5,19,36$

$5,36,37,65,23,32,68$

$5,53,65,10,54$

$22,30,42,17,33,5,20,37,47$

$30,51,23,33,1,42,65,10,21,70$

$22,33,51,70,1,5,9,42,43,46$

$20,30,21,22,1,36,40,42,43,51,64$

$33,3,43,1,5,19,9,32,36,42,51$

$44,43,14,16,34,70,1,3,11,12,19,30$

$43,46,1,3,19,20,46,33,48,5,9,26,30$

$44,1,3,19,20,46,33,48,5,9,26,30$

$3,43,5,9,20,26,46,65$

$5,19,20,26,43,32,44$

$3,23,1,5,9,19,37,42,43,48$

$5,37,43,22,23,33,44,61,3,20,26,30,36,42,46,65$

$37,13,66,1,3,42,6,19,20,26,30,36,43,51,53,65$

$5,42,17,1,25,66,3,26,36,48,51$

$37,17,5,51,22,25,33,70,1,3,20,26,30,35,61$

$37,42,70,35,51,21,25$

$21,17,70,42$

$35,33,70,17,22$

$16,17,21,30,35,42,46,14,22,34$

$14,34,70,41,46$

$16,34,46,70$

$14,16,11,12,46,44,70$

$33,66,1,5,20,37,65$

$28,19,20,26,30,43,3$

$37,42,17,69$

$12,34,46$

$11,34,46$

$39,43,26,27,37,44$

$4,48,44$ 
Table 5 (cont.)

Name or no.

Code

SR 15

SR 221

SR 198

SR 266

SR 29

Nocardia rubra

Streptomyces venezuelae

SR 202

Micromonospora sp.

SR 12 A

Bacillus subtilis

no.

Nocardia asteroides

$31,39,44,27$

4,44

4,48

$14,16,44,59$

5

1, 42

25

9, 33

41

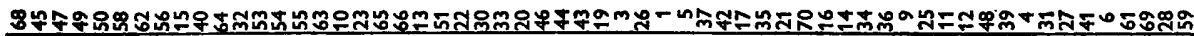

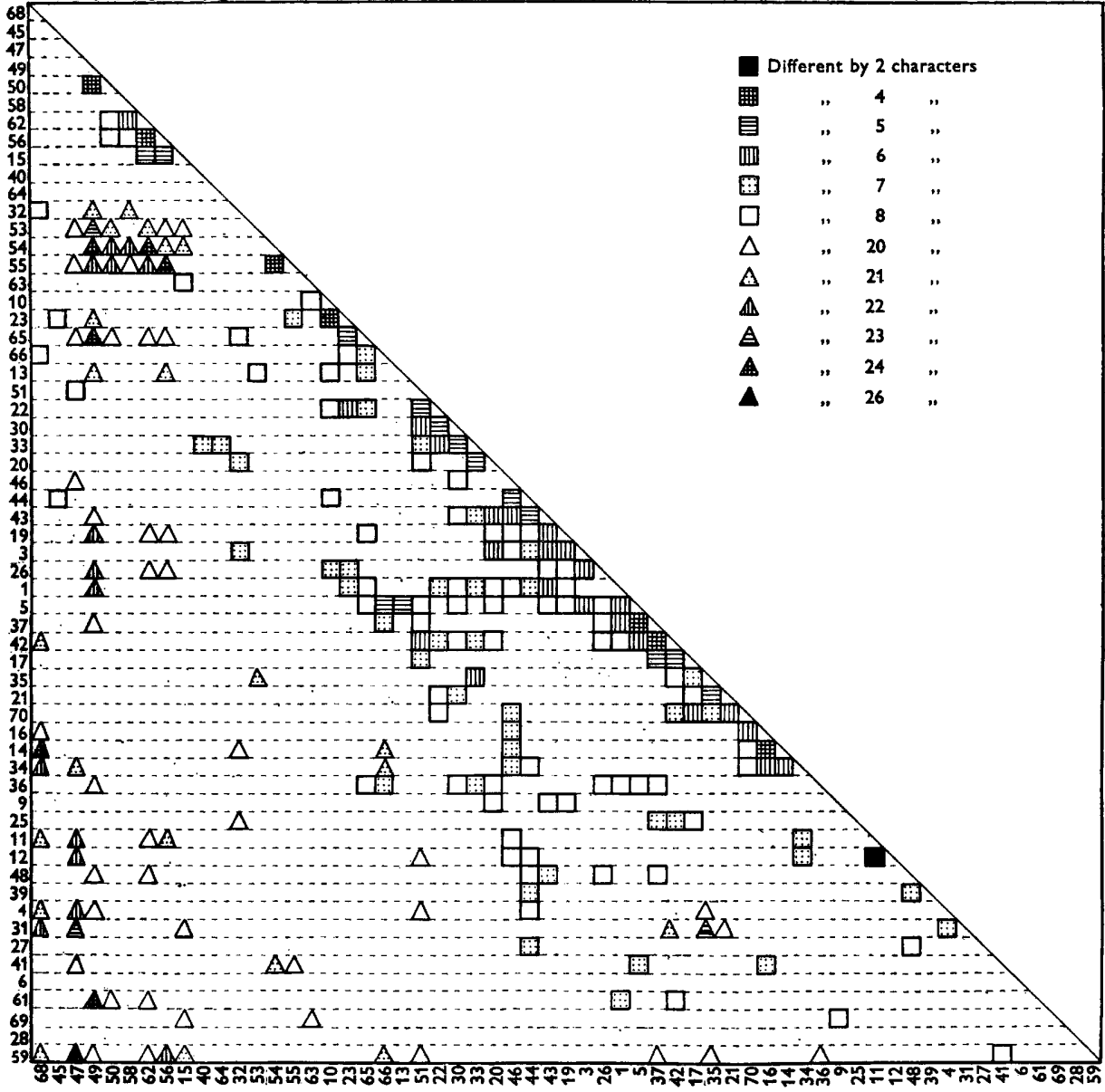

Fig. 3. Diagram showing the relationship between 64 cultures. The shading of squares indicates the number of characters by which similar cultures differ. The triangles indicate the number of characters by which dissimilar cultures differ. Intermediate relationships are not shown. The key for the culture numbers or names is given in Table 5 . 
and non-proteolytic all other named cultures corresponded closely with the descriptions given by Bergey's Manual (1957). Thornley (1960) reported that Pseudomonas could be differentiated on the basis of the anaerobic breakdown of arginine. All 64 cultures were tested for anaerobic arginine breakdown and of those which were Gram negative, penicillin resistant, and produced acid from glucose aerobically only six gave a positive arginine test. Those cultures were Pseudomonas fluorescens, Pseudomonas medicaginis, Achromobacter A1 and A2, Arthrobacter ureafaciens, and the rhizosphere isolate RS 83. Thus, according to Thornley, the so-called Arthrobacter ureafaciens, Achromobacter cultures, and SR 83 are really members of the genus $P$ seudomonas. It is interesting to note that in Table 5 these cultures have been grouped together on the basis of Affinity Index quite independently of the arginine test and showed a very poor relationship to the majority of the rhizosphere isolates.

\section{DISCUSSION}

The system of division on associated characters proved to be of no value in this particular case, firstly because of the lack of distinct groups within the range of bacteria considered, and secondly because of the somewhat complex nature of the analytical procedure. While it is true that where groups differ in many characters these characters will be associated, it is not necessarily true that where there are associated characters there will be taxonomic groups. It is considered that it is only rarely that the elaborate computation of associations as performed in this paper will be necessary. A simpler process would be to obtain groups by using the Affinity Index and to find differences between groups by inspection.

The best system for identifying the isolates is undoubtedly Skerman's key especially when the type cultures of the genera most likely to be encountered are included with the isolates. The key has several deficiencies. Firstly, it is based on Bergey's Manual and any deficiencies in the Manual are reflected in the key. Secondly, there is the difficulty in the standardization of testing procedures, which should largely be solved by using $A$ Guide to the Identification of the Genera of Bacteria (Skerman, 1959). The present paper arose out of this difficulty of technique standardization. Sperber \& Rovira (1959) demonstrated the presence of branching forms in many cultures which would normally be considered to have unbranched forms. This gave rise to their large groups of 'Arthrobacter' and 'Arthrobacter-likeNocardias', which upon re-examination and comparison with known cultures of these genera proved to be incorrectly identified. Nevertheless, the prevalence of branching amongst the rhizosphere cultures was an important observation and a further study of this phenomenon with type cultures seems necessary.

The relationships between bacteria are well shown by the use of Sneath's Similarity (or Affinity) Index. The limitations of this method lie in the sorting procedures and the selection of tests or characters to be used. A close examination of Fig. $\mathbf{3}$ shows that several cultures have in fact been missorted, and correction would require a rearrangement of the figure. However the authors believe this is not justified as a perfect arrangement is not possible. As there are only two positions equidistant from any organism in the linear order, a compromise must be used if there are more than two organisms with an equal relationship to any other organism. The presentation of the data as in Table 5 simplifies the sorting procedures as the relation- 
ships are more easily seen than in Fig. 3. The other limitations of this method lie in the selection of tests or characters to be used. If the natural groupings of the bacteria considered differ from one another in ten characters, then the chances of determining the groups will depend on how many of the ten good tests are selected and how many poor tests are added to the good tests. The larger the number of poor tests the more the result will tend towards one diffuse group. In discussing test selection for taxonomic purposes, Krassilnikov (1959) pointed out that a good test must be a repeatable test. He suggested that the loss of a character was not as important as the spontaneous gain of a character, and also emphasized the importance of morphology in taxonomy. Cowan (1955) posed the question that bacteria form a spectrum of gradually merging forms. In trying to determine whether this is the case for the rhizosphere bacteria, the two factors to be borne in mind are that the inclusion of too many poor tests would tend to give this result and that the demonstration of a range of bacteria is not sufficient to say that bacteria do not occur as natural taxonomic groups. If any of the types in the range is rare then this would be the place to make a taxonomic division. Thus a 'spectrum' implies not only a continual slight change in the type of bacteria, but also that the numbers of bacteria either remain constant for each type, or the numbers fall off slowly from some central type. The vast numbers of bacteria in the rhizosphere make measurement of the numbers of various types an extremely difficult task, liable to very large sampling errors. Conditions in the rhizosphere favour a large number of organisms from a great range of species, with common features such as being predominantly Gram-negative rods with a fast growth rate and the ability to rapidly utilize organic supplements (Lochhead, 1940; Rovira, 1956; Rouatt \& Katznelson, 1957; Katznelson \& Rouatt, 1957; Zagallo \& Katznelson, 1957).

The authors wish to thank Mr V. B. D. Skerman, Dr J. S. Bunt, Dr Rose Mushin and Mr G. D. Bowen for supplying known cultures; Mr J. R. Harris for suggestions on the Affinity Index; Misses G. Banos, J. Coulson and M. Dawes for technical assistance; and Dr R. J. Swaby for constant encouragement and advice.

\section{REFERENCES}

Bergey's Manual of Determinative Bacteriology (1957). 7th ed. Ed. R. S. Breed, E. D. G. Murray \& N. R. Smith. Baltimore: Williams and Wilkins.

Bunt, J. S. \& Rovira, A. D. (1955). Microbiological studies of some sub-antarctic soils. J. Soil Sci. 6, 119.

Clark, F. E. (1940). The types of bacteria associated with plant roots. Trans. Kans. Acad. Sci. 43, 75.

Clark, F. E. (1949). Soil micro-organisms and plant growth. Advanc. Agron. 1, 241.

ConN, H. J. (1948). Ths most abundant groups of bacteria in soil. Bact. Rev. 12, 257.

Cowan, S. T. (1955). Introduction: The philosophy of classification. J. gen. Microbiol. 12, 314.

HiLl, L. R. (1959). The Adansonian classification of the staphylococci. J. gen. Microbiol. 20, 277.

Katznelson, H., Lochiead, A. G. \& Timonin, M. I. (1948). Soil micro-organisms and the rhizosphere. Bot. Rev. 14, 543.

Katznelson, H. \& RouatT, J. W. (1957). Studies on the incidence of certain physiological groups of bacteria in the rhizosphere. Canad. J. Microbiol. 3, 265.

Krassilnikov, W. A. (1959). Species significance of antibiotic compounds in actinomyces. Microbiology, Moscoro (English Translation), 28, 168. 
Lochread, A. G. (1940). Qualitative studies of soil micro-organisms. III. Influence of plant growth on the character of the bacterial flora. Canad. J. Res. (C) 18, 42.

Lochread, A. G. \& Chase, F. E. (1943). Qualitative studies of soil micro-organisms. V. Nutritional requirements of the predominant bacterial flora. Soil Sci. 55, 185.

Moroney, M. J. (1957). Facts from Figures. London: Penguin.

Parker, C. A. (1955). Anaerobiosis with iron wool. Aust. J. exp. Biol. med. Sci. $33,33$.

Rouat, J. W. \& Katznelson, H. (1957). The comparative growth of bacterial isolates from rhizosphere and non-rhizosphere soils. Canad. J. Microbiol. 3, 271.

Rovira, A. D. (1956). Plant root excretions in relation to the rhizosphere effect. II. A study of the properties of root exudate and its effect on the growth of micro-organisms isolated from rhizosphere and control soils. Plant \& Soil, 7, 178.

Skerman, V. B. D. (1959). A Guide to the Identification of the Genera of Bacteria. Baltimore: Williams and Wilkins.

SNeAth, P. H. A. (1957a). Some thoughts on bacterial classification. J. gen. Microbiol. $17,184$.

SNeath, P. H. A. $(1957 b)$. The application of computers to taxonomy. J. gen. Microbiol. 17, 201.

Sneath, P. H. A. \& Cowan, S. T. (1958). An electrotaxonomic survey of bacteria. J. gen. Microbiol. 19, 551.

Sperber, J. I. (1958). The incidence of apatite-solubilizing organisms in the rhizosphere and soil. Aust. J. agric. Res. 9, 778.

Sperber, J. I. \& Rovira, A. D. (1959). A study of bacteria associated with the roots of subterranean clover and Wimmera rye grass. $J$. appl. Bact. $22,85$.

StaRkEY, R. L. (1958). Interrelation between soil micro-organisms and plant roots in the rhizosphere. Bact. Rev. 22, 154.

Thornley, M. J. (1960). The differentiation of Pseudomonas from other Gram-negative bacteria. J. appl. Bact. 23, 37.

Ulrich, J. A. (1944). New indicators to replace litmus milk. Science, 99, 352.

Zagallo, A. C. \& Katznelson, H. (1957). Metabolic activity of bacterial isolates from wheat rhizosphere and control soil. J. Bact. 73, 760. 